\title{
Lysine Intolerance in a Variant Form of Citrullinemia
}

\author{
ICHRO MATSUDA ${ }^{(22)}$, SHINICHIRO ARASHIMA, YASUJI IMANISHI, JIRO YAMAMOTO, IZUMI \\ AKABOSHI, SIGELU SHINOZUKA, AND NORIYUKI NAGATA \\ Department of Pediatrics and Medicine, Kumamoto University Medical School, and Department of Pediatrics, \\ Hokkaido University School of Medicine, Kumamoto, Japan
}

\section{Summary}

An oral loading of lysine (100 $\mathrm{mg}$ of lysine-HCL/ $\mathrm{kg}$ ) was performed in two patients, 18-and 23-yr-old, with a variant form of citrullinemia.

Serum citrulline levels were approximately 10 times higher than control level and lysine levels were within the normal range, in contrast to the classical form of the disease in which serum citrulline is approximately $\mathbf{1 0 0}$ times normal levels and hyperlysinemia is usually present.

After lysine loading, lysine levels rose sharply and clearance was decreased. Blood ammonia rose approximately 2.5 times. Lysine, citrulline, and arginine were markedly elevated in urine, collected 90-210 min after the lysine loading. Baseline homocitrulline and homoarginine excretion was elevated and increased further after the load.

\section{Speculation}

Lysine tolerance was impaired in two patients with citrullinemia, although baseline lysine levels were normal. Lysine seemed to be catabolized along the alternate urea cycle: lysine-homocitrullinehomoarginine-urea. Hyperammpnemia was aggravated, suggesting competition between lysine and ammonia for $\alpha$-ketoglutarate and inability to remove ammonia completely by these two alternate pathways.

Hyperlysinemia and homocitrullinemia are well documented in cases of hereditary urea cycle disorders, such as ornithine transcarbamylase (OCT) deficiency (10) and argininosuccinate synthetase (AS) deficiency $(2,16,20)$, suggesting abnormal lysine metabolism. In a variant form of AS deficiency, it was found that serum citrulline elevation was milder than in the classical form and serum lysine was normal $(8,13)$. It was, therefore, uncertain whether or not abnormal lysine tolerance is presented in such cases.

To answer this, lysine loading tests were performed in two patients with the disease. This proved to be useful in understanding the relationship between urea cycle and lysine metabolism.

\section{MATERIALS AND METHODS}

Two female patients with a variant form of citrullinemia were examined. Although detailed clinical observations were reported elsewhere $(8,13)$, these two cases are briefly summarized here.

Case 1 (13) is an 18-yr-old female patient who suffered from recurrent vomitting and delayed physical and mental development since early childhood. At 7 years of age, height was $99 \mathrm{~cm}$ (below 1 percentile); weight was $13.2 \mathrm{~kg}$ (below 1 percentile). Her IQ was 58. Hyperammonemia due to partial AS synthetase deficiency was diagnosed at the age of 13. AS synthetase activity in liver tissue was $18 \mu \mathrm{m} \mathrm{mole} / \mathrm{g} / \mathrm{hr}$ (control 50.0 ) with a $\mathrm{Km}$ of $3 \times 10^{-3} \mathrm{M}$ (control $3.3 \times 10^{-4} \mathrm{M}$ ). All other urea cycle enzymes were normal. Serum ammonia concentration ranged between $420-610 \mu \mathrm{g} / \mathrm{dl}$. Blood aminoacids are listed in Table 1.

Case $2(8)$ is a 23 -yr-old female patient whose physical growth had been delayed since childhood and mental development was retarded. Recurrent vomiting, nausea, and headache were chief complaints from $17 \mathrm{yr}$ of age. Several episodes of delirium had also occurred.

Hyperammonemia ranged from $240-540 \mu \mathrm{g} / \mathrm{dl}$ and the EEG pattern was abnormal.

Citrulline levels in serum and cerebrospinal fluid were elevated. Lymphoid cell line was established from the patient after incu-

Table 2. Serum lysine and ammonium levels after lysine loading

\begin{tabular}{clccc}
\hline & & Before & $2 \mathrm{hr}$ & $4 \mathrm{hr}$ \\
\hline Lysine levels & Case 1 & 5.5 & 42.0 & 74.7 \\
$(\mu$ mole $/ \mathrm{d} \mathrm{l})$ & Case 2 & 11.8 & 38.6 & 43.4 \\
& Control & 14.7 & 23.4 & 19.5 \\
& & 12.1 & 21.3 & 11.5 \\
& & & & \\
Ammonia & Case 1' & 167 & 222 & 381 \\
$(\mu \mathrm{g} / \mathrm{dl})$ & Case 2 & 109 & 154 & 284 \\
& Control & 92 & 78 & 57 \\
& & 56 & 83 & 56 \\
\hline
\end{tabular}

1 With restriction of protein in their diet and after administration of lactulose, blood ammonia level was controlled below $200 \mu \mathrm{g} / \mathrm{dl}$.

Table 1. Serum amino acids ${ }^{1}$

\begin{tabular}{lcccc} 
& Case 1 & Case 2 & Control $^{2}$ & Classical $^{3}$ \\
Glutamate & $43.5-450.0$ & $373-430$ & $250 \pm 23$ & $129-196$ \\
Lysine & $55.0-124.5$ & $118-220$ & $187 \pm 30$ & $379-400$ \\
Citrulline & $125-235$ & $124-240$ & trace-20 & $1176-1470$ \\
Cystine & $24-30$ & $9-31$ & trace-40 & trace-89 \\
Ornithine & $75-102$ & trace-80 & trace-110 & $43-124$ \\
Arginine & $71-84$ & $14-52$ & $64 \pm 9$ & $68-82$ \\
\hline
\end{tabular}

Values are expressed in $\mu$ moles/liter, and other amino acid levels were in normal range.

"Control of our laboratory.

"Cited from Scott-Emuakpor et al. (16). 
Table 3. Urinary amino acids after lysine loading ${ }^{1}$

\begin{tabular}{|c|c|c|c|c|c|c|}
\hline & \multicolumn{2}{|c|}{ Control } & \multicolumn{2}{|c|}{ Case 1} & \multicolumn{2}{|c|}{ Case 2} \\
\hline & $\mathbf{A}$ & $\mathbf{B}^{2}$ & $\mathbf{A}$ & B & A & B \\
\hline Lysine & $186 \pm 97$ & 868.8 & 100.4 & 4273.3 & 205.9 & 2462.6 \\
\hline Cystine & $150 \pm 59$ & 82 & 40.4 & 204.3 & 58.8 & 81.4 \\
\hline Ornithine & $52 \pm 10$ & 27.5 & 11.8 & 46.5 & 32.9 & 62.6 \\
\hline Arginine & $30 \pm 19$ & 18.6 & 25.6 & 430.6 & 176.6 & 1090.5 \\
\hline Citrulline & $0-5$ & $0-5$ & 157.8 & 311.3 & 388.6 & 2299.4 \\
\hline Homocitrulline & $0-30$ & 77 & 90.2 & 578.3 & 132.4 & 1161.2 \\
\hline Homoarginine & $\mathrm{ND}^{3}$ & 31 & ND & 95.3 & 66.5 & 170.9 \\
\hline Urea $^{4}$ & $5.3 / 5.4$ & $5.4 / 5.5$ & & & 3.8 & 4.9 \\
\hline
\end{tabular}

' A: before the loading; B: after lysine loading (100 mm/ $\mathrm{kg})$. Urine was collected during the period from $1.5-3.5 \mathrm{hr}$ after the loading. Values are expressed as $\mu$ mole/g creatinine.

Mean of 3 samples.

${ }^{3} \mathrm{ND}$ : not detectable.

${ }^{4} \mathrm{Mg} / \mathrm{mg}$ creatine.

bation with Epstein-Bar virus as described earlier (14). Utilization of citrulline in the lymphoid cell line was reduced $(1,18)$. Liver or skin biopsy were not performed, because permission was denied.

\section{LYSINE LOADING TESTS}

After an 8 -hr fast, $100 \mathrm{mg}$ lysine-HCL/ $\mathrm{kg}$ was given orally. Blood samples were taken before, and 2 and $4 \mathrm{hr}$ after the load: urine specimens were collected before, and from 90-210 min after the load. Amino acid analayses were performed by use of the HITACHI Model KLA-S amino acid analyzer. Ammonia levels in serum were measured by a method described previously. (12)

\section{RESULTS}

Baseline levels of citrulline were increased approximately 10 times, glutamate was slightly elevated, and lysine levels were normal in both patients. Cystine, ornithine, and arginine levels were also normal (Table 1).

After the oral load, serum lysine and blood ammonia were markedly elevated in both patients, whereas in the control, lysine elevation was slight and ammonia was essentialy unchanged (Table 2). Serum citrulline, cystine, ornithine, and arginine levels were essentialy unchanged both in the patients and the control.

Increase in urinary lysine, citrulline, arginine homocitrulline, and homoarginine excretion were recorded after the load (Table 3 ). Pipecolic acid and saccharopine were not detected after the load.

\section{DISCUSSION}

Genetic heterogeneity exists in citrullinemia $(9,12,16)$, as in other urea cycle disorders $(13,19)$. In the classical form of the disease, serum citrulline levels are elevated up to 100 times above the control value. Serum lysine and urinary homocitrulline and homoarginine are also increased $(2,16,20)$. By contrast, serum citrulline elevation was relatively minor in the present cases, and urinary homocitrulline and homoarginine were either normal or only slightly elevated. A variant form of the disease was therefore diagnosed (12). A link between hyperammonemia and abnormal lysine catabolism has been documented in congenital lysine intolerance (4), as well as in in some urea cycle disorders $(2,10,16,17$, 20 ), and in hyperornithinemia (6). Several explanations for the elevated serum ammonia after lysine loading may be offered: 1) because competition between lysine and ammonia for $\alpha$-ketoglutarate is possible (10), further loading with lysine may induce a decrease of the $\alpha$-ketoglutarate reserve which subsequently results in an increase of serum ammonia, 2) lysine is an inhibitor of arginase and, therefore, may induce hyperammonemia $(4,5), 3)$ a relationship seemes to be exist between Krebs-Henseleit urea cycle and the alternate urea cycle, as discussed later in this paper.

Observations in our patients suggest that elevated ammonia, induced by lysine loading may produce further formation of citrulline, because urinary excretion increased markedly after the load. The rise in urinary arginine may have several cause. Because lysine, arginine, ornithine, and cystine participate in a common transport system (15), lysine might compete for tubular reabsorption and induce increased excretion of all these aminoacids. Urinary cystine and ornithine rose slightly, but not above the normal range. Alternately, arginine may rise because of arginase inhibition by lysine. The presence of an alternate urea cycle (i.e., lysine-homocitrulline-homoarginine-urea) has been posturated by Scott-Emuakpor et al. (16) in order to explain the increased amount of urinary homocitrulline and homoarginine in classical citrullinemia.

Cathelineau et al. (3) cited experiments of bovine liver, which indicated that lysine and homocitrulline were substrates of corresponding enzymes of the Krebs-Henseliet urea cycle, OCT, and AS synthetase. Although the hypothesis of Cathelineau, et al. (3) is possible in some cases (17), it would not account for the observation that urinary homocitrulline was elevated in carbamylphosphate synthetase deficiency (7) and in OCT deficiency (10).

Elevation of urinary homoarginine in the present case also speaks against this hypothesis. Levin et al. (11) proposed that elevated citrulline may impair the lysine-saccharopine pathway and that this impairment of lysine utilization could induce elevation of homocitrulline and homoarginine. The present observation of increased urinary excretion of homocitrulline and homoarginine after lysine loading may support the hypothesis of the presence of alternate urea cycle as orginally proposed by Scott-Emuakpor et al. (16).

This pathway was activated by lysine induced hyperammonemia.

\section{REFERENCES AND NOTES}

1. Akaboshi, I., Yamamoto, J., Matsuda, I., Shinozuka, S., and Nagata, N.: Lymphoid cell lines form variant form of citrultinemia (to be published)

2. Buist. N. R. M., Kennaway. N. G., Hepburn, C. A.. Strandholm, J. J., and Ramberg. D. A.: Citrullinemia: investigation and treatment over a 4-yr period. J. Pediat., 85: 208 (1974).

3. Cathelineau. L.. Sandubray, J. M. Charpentier. C., and Polonovski, C.: Letter to the Editor Pediatr. Res.. 8: 57 (1974).

4. Colombo, J. P.. Burgi, W., and Rossi. E.: Congenital lysine intolerance with periodic ammonia intoxication: A defect in L--lysine degradation. Metabolism. 10: 910 (1967).

5. Colombo, J. P.. Ridrterich. R.. Donath. A.. Spahr, A., and Rossi. E.: Congenital lysine intolerance with periodic ammonia intoxication. Lancet $1: 1014$ (1964).

6. Fell, V., Pollitt, R. J., Sampson, G. A., and Wright, T.: Ornitinemia, hyperammonemia, and homocitrullinuria. Am. J. Dis. Child., 127: 752 (1974).

7. Gatfield, P. D., Taller, E., Wolfe, D. M., and Haust, M. D.: Hyperornithinemia, hyperammonemia, and homocitrullinemia associated with decreased carbanryl phosphate synthetase I activity. Pediatr. Res., 9: 488 (1975).

8. Imanishi, K., Okajima, T., Ideta. T., Ueno. H., and Matsumoto, Y.: Juvenile hepatocerebral disease with citrullinemia. Clin. Neurology.. 16: 389 (1976).

9. Kennaway, N. G.. Harwood, P. J., Ramberg. D. A., Koler, R. D., and Buist. N. 
R. M.: Citrillinemia: enzymatic evidence for genetic heterogenetity. Pediatr. Res., 9: 554 (1975)

10. Krieger, I., Bachmann, C., Gronemeyer, W. and Cejka. J.: Propionic acidemia and hyperlysinemia in a case with ornithine transarbamylase (OCT) defiency. J. Clin. Endocrinol. Metab., 43: 796 (1976).

11. Levin, B., Oberholzer, V. G., and Palmer, T.: Letter to the Editor: citrullinemia and an alternatine urea cycle. 7: 728 (1973).

12. Matsuda, I.. Anakura, M., Arashima, S., Saito, Y., and Oka, Y.: Variant form of citrullinemia. J. Pediatr., 88: 824 (1976)

13. Matsuda. I., Arashima, S., Nambu. H.. Takekoshi, Y., and Anakura, M.: Hyperammonemia due to mutant enzyme of ornithine transcarbamylase. Pediatrics, 48: 595 (1971)

14. Matsuda, I., Yamamoto, J., Nagata, N.. Nimoniya, N., Akaboshi, I., Ohtuska, H., and Katsuki, T.: Lysosomal enzyme activity in cultured lymphoid cell lines. Clin. Chim. Acta, 80: 483 (1977).

15. Robson, E. B.. and Rsoe, G. A.: The effect of intravenous lysine on the renal clearance of cystine, arginine, and ornithin in normal subjects, in patients with cystinuria and Fanconi syndrome and their relatives. Clin. Sci., 16: 75 (1957).

16. Scott-Emuakpor, A., Higgis, J. V. nad Kohrman, A. F.: Citullinemia: a new case, with implications concerning adaptation to defective urea synthesis. Pediatr.
Res., 6: 626 (1972).

17. Sogawa, H.. Oyanagi, K., and Nakao, T.: Periodic hyperammonemia, hyperlysinemia, and homocitrullinuria associated with decreased argininosuccinate synthetase and arginase activities. Pediatr. Res.. 11: 949 (1977).

18. Spector, E. B., and Bloom, A. D.: Citrullinemic lymphocytes in long term culture. Pediatr. Res., 7: 700 (1973).

19. Van Der Heiden, C., Desplanque, J., and Bakker. H. D.: Some kinetic properties of liver ornithine carbamyl transferase (OCT) in a patient with OCT deficiency. Clin. Chim. Acta, 80: 519 (1977).

20. Vidalihert, M., Levin, B., Dautrevaux, M., Paysant, P., Gelot, S., Bandonell, Y. Pierson, M., and Niemann. N.: Citrullinemia. Arch. Fr. Pediatr., 28: 521 (1971).

21. This research was supported by a Research Grant aided by the Ministry of Health and Welfare of Japan for the Research on Reye's Syndrome 1977 and a Research Grant 249018 from the Ministry of Education of Japan.

22. Requests for reprints should be addressed to: I. Matsuda M. D., Department of Pediatrics, Kumamoto University, Medical School, 860, Kumamoto. Japan.

23. Received for publication July 25, 1978.

24. Accepted for publication October 24, 1978 